\title{
Population compliance with national dietary recommendations and its determinants: findings from the ORISCAV-LUX study
}

\author{
Ala'a Alkerwi ${ }^{1,2 *}$, Nicolas Sauvageot ${ }^{1}$, Anne Nau $^{1}$, Marie-Lise Lair $^{1}$, Anne-Françoise Donneau ${ }^{2}$, \\ Adelin Albert ${ }^{2}$ and Michèle Guillaume ${ }^{2}$ \\ ${ }^{1}$ Centre de Recherche Public Santé, Centre d'Etudes en Santé, Grand-Duchy of Luxembourg \\ ${ }^{2}$ Ecole de Santé Publique, Université de Liège, Belgium
}

(Submitted 13 July 2011 - Final revision received 3 January 2012 - Accepted 6 January 2012 - First published online 8 February 2012)

\section{Abstract}

The objective of the present study was to determine the proportion of adults meeting national recommendations for food and nutrient intake and to identify the demographic, socio-economic and behavioural factors that may contribute to weaken dietary compliance. ORISCAV-LUX is a cross-sectional study that took place in Luxembourg (2007-8). A representative stratified random sample of 1352 adults aged 18-69 years participated in the nationwide cardiovascular health survey. A FFQ was used to estimate food intake. Radar charts were built to compare graphically the compliance of the participants with different key dietary guidelines on the same set of axes. The thirteen foodand nutrient-based recommendations were scored and summed to create a recommendation compliance index (range -0.5 to 14 ). Ordinal logistic regression analyses were performed to determine the factors contributing to poor dietary compliance. Several food- and nutrientbased guidelines were insufficiently respected compared with others. The greatest gaps occurred in the adherence to grain and dairy product consumption guidelines, as well as to total fat and notably to SFA recommendations. Age, country of birth, economic status, smoking status and subject's awareness of the importance of balanced meals emerged as independently associated with weak dietary compliance. Obese subjects conformed more to dietary recommendations compared with normal-weight subjects. The findings underscore the need for specific nutrition education messages along with targeted interventions. Efforts should be continued to increase population awareness of the importance of a healthy lifestyle and a balanced diet.

\section{Key words: National dietary recommendations: Nutrition education: Dietary compliance: Epidemiological studies}

The burden of chronic diseases, such as cancer, CVD, obesity, diabetes and osteoporosis, is rapidly increasing worldwide. Lifestyles imposed by modern civilisation, particularly dietary habits, have been shown to be centrally involved in their multi-factorial causation ${ }^{(1,2)}$. Beyond the appropriate medical treatment for those already affected, the public health approach of primary prevention is considered to be the most cost-effective, affordable and sustainable course of action to cope with the global chronic disease epidemic ${ }^{(2)}$. Currently, healthy eating promotion messages therefore occupy a prominent position in prevention activities ${ }^{(3)}$

The Grand-Duchy of Luxembourg is a tiny central European country with 511800 inhabitants of multiple nationalities. Apart from native people, $43.2 \%$ of the population are well-integrated foreign residents, mostly Portuguese (15.9\%), French (6.1\%), Italians $(3.5 \%)$ and Belgians $(3.3 \%)^{(4)}$. Although the majority is of European origin, this mosaic demographic characteristic produces multicultural dietary habits. Beyond cancer, cardiovascular mortality is considered to be the top leading cause of death, accounting over the past 10 years for about $40 \%$ of total mortality in Luxembourg ${ }^{(5)}$. In addition, the potentially modifiable cardiovascular risk factors, individually as dyslipidaemia (69.9\%), hypertension $(34.5 \%)$, obesity $(20 \cdot 9 \%)$, diabetes $(4.4 \%)$, or in clustering as the metabolic syndrome (24.7\%), affect a large proportion of the population and have, worryingly, started to appear earlier in life. In fact, the young age groups have already presented a striking multiple risk profile, with a significant sex-specific difference ${ }^{(6,7)}$.

During the last two decades, successive sets of dietary guidelines began to emerge in the USA and Europe. Several governments, including that of Luxembourg, moved on to implement national plans and to develop nutritional recommendations, to deal with the increasing public health challenges related to diet and health. In 2006, the national public health authorities in Luxembourg launched an intensive campaign with the aim of providing the general population with food- and nutrient-related guidelines. Representative data of

Abbreviations: ORISCAV-LUX, Observation of Cardiovascular Risk Factors in Luxembourg; RCI, recommendation compliance index.

*Corresponding author: Dr Ala'a Alkerwi, fax +352 26970 719, email alaa.alkerwi@crp-sante.lu 
population dietary intake were delivered from the 'Observation of Cardiovascular Risk Factors in Luxembourg' (ORISCAV-LUX) survey 2007-8, to assess the needs for a targeted nutrition education programme. The purpose of the study was to provide policy makers and professionals involved in nutrition education with reliable data to address efficient and targeted interventions. While previous international studies have shown an interest in the nutritional status of specific vulnerable groups ${ }^{(8,9)}$, only a few studies have focused on the general, presumably healthy, adult population. Nevertheless, inadequate diet constitutes a potential health threat and the achievement and then the maintenance of good dietary habits are of major public health concern. Underpinning the adequacy of dietary intake, or, in other words, the compliance with dietary guidelines depends on many health-related, socio-cultural and behavioural factors. From a prevention standpoint, the objectives of the present paper are to assess the current degree of adherence to the national dietary recommendations, and to identify the factors contributing to weak dietary compliance.

\section{Methods}

\section{Study population}

The ORISCAV-LUX survey was the first nationwide epidemiological and nutritional cross-sectional survey to take place in Luxembourg. The study provided representative data on adults aged 18-69 years, residing in Luxembourg, based on a weighted random sample stratified according to age, sex and district, selected from the national health insurance registry. The distribution of selected subjects in each stratum was proportional to their distribution in the source population. Further details concerning the aims, data collection, sample representativeness and non-dietary baseline data have been reported elsewhere ${ }^{(6,10)}$. Briefly, a total of 1432 participants visited the nearest study centre after phone appointment. At the interview, the trained research staff provided the participants with information on the study background and objectives, gave detailed instructions about how to fill in the FFQ, helped the participants individually to complete dietary information and then checked the correctness of completed questionnaires. Further information regarding the demographic, socio-economic and lifestyle behaviours was collected as well as direct blood pressure and anthropometric measurements.

\section{Demographic, socio-economic and lifestyle data}

The self-reported questionnaire, administered during the interview, provided data for individual characteristics. These included sex, age, district of residence, country of birth, education, income and marital status. The above variables were categorised as follows: sex: men, women; age: 18-29 years, 30-49 years, 50-69 years; district of residence: Diekirch, Grevenmacher, Luxembourg; country of birth: European, nonEuropean, Portuguese, Luxembourgish; education: primary, secondary, tertiary level; income: living above, below poverty threshold; marital status: live alone, live with partner.
The participant's awareness of the importance of eating a balanced meal was assessed via the question 'what importance do you accord to balanced meals in order to remain in good health?' The answers were classified as: very important, enough importance, little importance. Smoking status was defined as smoker or non-smoker. Full details concerning the calculation of variables have been published elsewhere ${ }^{(11)}$.

\section{Anthropometric data}

Weight and height were measured according to standard protocol procedures, as reported earlier ${ }^{(6)}$. BMI was calculated by dividing weight $(\mathrm{kg})$ by the square of height $(\mathrm{m})$. Based on the International Obesity Task Force, convened by the WHO, subjects with BMI $<18.5,18.5-24.9,25-29.9$ and $\geq 30.0 \mathrm{~kg} / \mathrm{m}^{2}$ were considered as underweight, normal, overweight and obese, respectively ${ }^{(12)}$.

\section{Dietary data}

Dietary intake data were collected using a self-administered semi-quantitative $F_{F Q}{ }^{(13)}$. Recruitment was conducted over a period of 15 months, between November 2007 and January 2009, hence aiming to reduce the effect of seasonal variation $^{(14)}$. However, with the availability of large amounts of imported fruit and vegetables all year round, the effect of seasonal variation on diet today is probably less than in it was before. The participants reported the frequency of consumption and portion size of 134 items over the last 3 months. Each item is defined by a series of foods or beverages. The participants reported the frequency of consumption of each food group on the basis of six levels of frequencies, ranging from 'rarely or never' (i.e. less than once per day) to 'two or more times per day'. Standard serving sizes of food or beverage were either specified on the FFQ (for example, soup spoon) or estimated based on a photographic manual ${ }^{(15)}$, provided as a reference for the evaluation of consumed portions. Food and beverages from the FFQ were categorised into nine major food groups: starchy food, fruits, cooked and raw vegetables, meat-poultry-fish-eggs, prepared dishes, dairy products, fats, drinks (alcoholic and non-alcoholic) and miscellaneous. Nutrient intakes were calculated by multiplying the consumption frequency of each food by the nutrient content of specified portions. Nutrient values were obtained from the French 'SUpplementation en VItamines et Mineraux AntioXydants' (SU.VI.MAX) Food Composition Database ${ }^{(16)}$.

In the present study, two patients aged 70 years and forty-three participants with non-reliable reporting in the FFQ of the frequency of consumption and portion size were excluded. Next, six subjects who quoted highly implausible data for the frequency and quantity of certain food groups were also discarded. Finally, after the calculation of individual nutrient intakes, twenty-nine participants were eliminated because of too many outlying values (i.e. nutrient intakes outside the 1-99 percentile range). Finally, a total of 1352 subjects were included in the statistical analysis. The sample was weighted to account for the complex sampling design and for non-response. 


\section{Recommendation compliance index}

A recommendation compliance index (RCI) was developed to measure the degree of adherence to national dietary guidelines ${ }^{(17)}$. It is a composite of thirteen quantified national recommendations regarding the intake of food and nutrients. Table 1 describes the construction of the RCI, the nutritional indicators, the intake goals (RDA) and the scoring criteria. Globally, components 1-7 measure the degree to which the participant's diet conforms to the seven food-based guidelines. Components 8-13 measure the degree to which the participant's diet conforms to the six nutrient-based guidelines. The cut-off points and scoring criteria were defined basically according to the adherence to national intake goals, as well as clinical evidence and previously published epidemiological studies $^{(18,19)}$. Specifically, the French 'Programme National Nutrition Santé' guideline scoring criteria ${ }^{(20)}$ were applied with simple adaptation, due to cultural convergence and the important similarity of several key dietary guidelines. The general approach for scoring was to attribute points according to how participants met with recommendations ${ }^{(14)}$. Respondents who met a given dietary goal received one point. In the case of non-adherence to that national dietary recommendation, zero points were attributed; otherwise, intermediate points were attributed to subjects who were closely attaining the given recommendation. By this method of scoring, a penalty for harmful overconsumption was considered (for example,

Table 1. Construction of the recommendation compliance index

\begin{tabular}{|c|c|c|c|}
\hline Components & National intake goals & Scoring criteria* & Score \\
\hline \multicolumn{4}{|l|}{ Food-based recommendations } \\
\hline Grain products $†$ & $\geq 3$ times $/ \mathrm{d}$ & $\begin{array}{l}{[0-1[\text { times } / d} \\
{[1-3[\text { times } / d} \\
{[3-6[\text { times } / d} \\
\geq 6 \text { times } / d\end{array}$ & $\begin{array}{c}0 \\
0.5 \\
1 \\
0.5\end{array}$ \\
\hline Dairy products & $\geq 3$ times $/ \mathrm{d}$ & $\begin{array}{l}{[0-1[\text { times } / \mathrm{d}} \\
{[1-2 \cdot 5[\mathrm{times} / \mathrm{d}} \\
{[2.5-3.5] \mathrm{times} / \mathrm{d}} \\
>3.5 \mathrm{times} / \mathrm{d}\end{array}$ & $\begin{array}{c}0 \\
0.5 \\
1 \\
0.5\end{array}$ \\
\hline Meat-poultry-fish-eggs & $1-2$ times/d & $\begin{array}{l}0 \\
] 0-1[\text { times } / \mathrm{d} \\
{[1-2] \text { times } / \mathrm{d}} \\
>2 \text { times } / \mathrm{d}\end{array}$ & $\begin{array}{c}0 \\
0.5 \\
1 \\
0\end{array}$ \\
\hline Sea food & $\geq 2$ times/week & $\begin{array}{l}<2 \text { times/week } \\
\geq 2 \text { times/week }\end{array}$ & $\begin{array}{l}0 \\
1\end{array}$ \\
\hline Fruits and/or vegetables & $\geq 5$ servings/d & $\begin{array}{l}{[0-3.5[\text { servings/d }} \\
{[3.5-5[\text { servings/d }} \\
{[5-7.5[\text { servings/d }} \\
\geq 7.5 \text { servings/d }\end{array}$ & $\begin{array}{c}0 \\
0.5 \\
1 \\
2\end{array}$ \\
\hline Saltł & $5-10 \mathrm{~g} / \mathrm{d}$ & $\begin{array}{l}>12 \mathrm{~g} / \mathrm{d} \\
] 10-12] \mathrm{g} / \mathrm{d} \\
{[5-10] \mathrm{g} / \mathrm{d}} \\
<5 \mathrm{~g} / \mathrm{d}\end{array}$ & $\begin{array}{l}-0.5 \\
0 \\
1 \\
1\end{array}$ \\
\hline Non-alcoholic drinks & $\geq 1.5$ litres $/ d$ & $\begin{array}{l}<1 \text { litre/d } \\
{[1-1.5[\text { litres } / d} \\
\geq 1.5 \text { litres } / d\end{array}$ & $\begin{array}{c}0 \\
0.5 \\
1\end{array}$ \\
\hline \multicolumn{4}{|l|}{ Nutrient-based recommendations } \\
\hline Total fat§ & $\leq 35 \% \mathrm{E}$ & $\begin{array}{l}>35 \% E \\
\leq 35 \% E\end{array}$ & $\begin{array}{l}0 \\
1\end{array}$ \\
\hline SFA & $\leq 10 \% \mathrm{E}$ & $\begin{array}{l}>10 \% \mathrm{E} \\
\leq 10 \% \mathrm{E}\end{array}$ & $\begin{array}{l}0 \\
1\end{array}$ \\
\hline Total carbohydrates $\|$ & $>45 \% \mathrm{E}$ & $\begin{array}{l}\leq 45 \% \mathrm{E} \\
] 45-75] \% \mathrm{E} \\
>75 \% \mathrm{E}\end{array}$ & $\begin{array}{c}0 \\
1 \\
0.5\end{array}$ \\
\hline 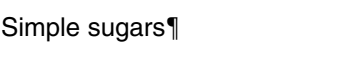 & $\leq 10 \% \mathrm{E}$ & $\begin{array}{l}>10 \% \mathrm{E} \\
\leq 10 \% \mathrm{E}\end{array}$ & $\begin{array}{l}0 \\
1\end{array}$ \\
\hline Total protein & $15-20 \% \mathrm{E}$ & $\begin{array}{l}<15 \% \mathrm{E} \\
{[15-20] \% \mathrm{E}} \\
>20 \% \mathrm{E}\end{array}$ & $\begin{array}{l}0 \\
1 \\
0\end{array}$ \\
\hline Total fibres & $>25 \mathrm{~g} / \mathrm{d}$ & $\begin{array}{l}\leq 25 \mathrm{~g} / \mathrm{d} \\
>25 \mathrm{~g} / \mathrm{d}\end{array}$ & $\begin{array}{l}0 \\
1\end{array}$ \\
\hline
\end{tabular}

$\% \mathrm{E}$, percentage of total daily energy intake.

* Brackets can be read as follows: ']x' or 'x[', boundary not included; '[x' and 'x]', boundary included.

$\dagger$ Grain products refer to all types of bread, cereals, muesli, pastries, potatoes, rice, pasta and pulses.

$¥$ This variable does not include added salt to food. The scoring criteria and cut-off points were based on the French Programme National Nutrition Santé Guideline Score with adaptation ${ }^{(20)}$.

$\S$ Refers to the total fat of the diet (oils and fats added and contained in the foods).

$\|$ The scoring criteria and cut-off points were defined according to the WHO recommendations ${ }^{(2)}$.

I The term 'simple sugars' refers to all monosaccharides and disaccharides naturally present in foods (honey, syrups and fruit) and added by the manufacturer, cook or consumer. 
salt intake), and a reward for beneficial overconsumption (for example, fruit and vegetable consumption) ${ }^{(18,20)}$ (Table 1). The overall index obtained by summing the thirteen components ranges between -0.5 (due to a negative half point for excessive salt intake) and 14 points ( 2 points for high daily fruit and vegetable servings), where a higher degree of adherence results in higher scores. To account for energy intake and the tendency to overestimate self-reported consumption, in the design of the RCI, penalties were applied to participants who had energy intake 5\% higher than their calculated energy needs, as estimated using the BMR and physical activity ${ }^{(20)}$. The RCI was constructed to summarise information on the population's dietary compliance and to create a more simplified picture of its relationship with socio-economic, behavioural and health-related factors.

\section{Physical activity}

Self-reporting of physical activity during the last $7 \mathrm{~d}$ before the interview was assessed by using the International Physical Activity Questionnaire (IPAQ) ${ }^{(21)}$, which categorises the population into three levels: physically inactive, moderately active and active, as recommended by the IPAQ group of experts ${ }^{(22)}$.

\section{Ethical aspects}

The present study was conducted according to the guidelines laid down in the Declaration of Helsinki and all procedures involving human subjects were approved by the National Research Ethics Committee and the National Commission for Private Data Protection. Written informed consent was obtained from all the subjects.

\section{Statistical analysis}

The radar charts were built to display how various dietary objectives were met and to illustrate the gap between the current state (percentage of participants currently adherent to each dietary recommendation) and the ideal situation (100\% compliance). Sex- and age-specific differences in the compliance rate for each food- and nutrient-based recommendation were tested by classical $\chi^{2}$ statistics.

The RCI was split into four groups based on distribution quartiles. It ranged from a 'poor compliance' (RCI $<5.50$ ) to a 'good compliance' ( $\mathrm{RCI} \geq 8$ ), with the two intermediate categories (5.50-6.99) and (7-7.99) defined as 'needs improvement'. Univariate analyses, via a trend analysis and ordinal logistic regression, identified the factors significantly associated with a good degree of compliance (the 4th quartile was taken as the reference category of the dependent variable: $\mathrm{RCI})$. The independent variables included age, sex, marital status, country of birth, economical status, education level, smoking habits, BMI, and participant's awareness of the importance of balanced meals to maintain good health. The parallel lines assumptions (which mean that the location parameters are equivalent across the levels of the dependent variable and which are necessary to perform an ordinal regression) were met for each variable. The cumulative OR and the respective $95 \% \mathrm{CI}$ were estimated to identify the variables independently associated with the weak degree of adherence to national recommendations. Then, the socioeconomic, behavioural and health-related variables found significant in the univariate analysis were combined in a stepwise multivariate statistical analysis. Results were considered significant at the $5 \%$ critical level $(P<0 \cdot 05)$. All statistical analyses were performed by using PASW ${ }^{\circledR}$ for Windows ${ }^{\circledR}$ version 18.0 software (formerly SPSS Statistics Inc.) and survey procedure for complex sampling designs.

\section{Results \\ Compliance with food-related guidelines}

Sex- and age-specific compliance rates with individual foodand nutrient-based guidelines were calculated and depicted in radar charts for the adults residing in Luxembourg (Figs. 1-4).

Globally, women had a better compliance with national guidelines than men; differences were significant for fruits and vegetables, dairy products and salt. From a public health point of view, the participants who consumed less than $5 \mathrm{~g}$ salt/d (below the national recommended range) were included in the group of compliers with that dietary goal (Fig. 1).

Overall, the older age groups were more compliant with food-based recommendations than the younger ones, in particular the guidelines for salt, fruits and vegetables, sea food and meat-poultry-fish-eggs (Fig. 2).

\section{Compliance with nutrient-related guidelines}

While approximately $80 \%$ of the population was conforming to the simple sugars guideline (less than $10 \%$ of total energy intake), the adherence to adequate consumption of total fats (maximum $35 \%$ of total daily energy intake) and particularly of SFA (less than $10 \%$ of daily energy intake) was dramatically low in both sexes (31 and 12.4\%, respectively) (Fig. 3).

There were significant age-specific differences with regard to simple sugar and total carbohydrate consumption. Older individuals were more likely to follow the simple sugars guideline than younger individuals; however, younger individuals respected more the total carbohydrates recommendation than older individuals (Fig. 4).

\section{Distribution of compliance according to demographic, socio-economic and lifestyle behaviours}

Table 2 describes the distribution of the categorised RCI according to demographic, socio-economic and lifestyle behaviours. There was no substantial sex-specific difference with regard to the quartiles of RCI, but there was an age-specific difference $(P=0.42, P<0.0001$, respectively). The degree of compliance varied significantly with respect to country of birth, marital status, economic status, smoking status and subjective awareness of the importance of eating balanced 


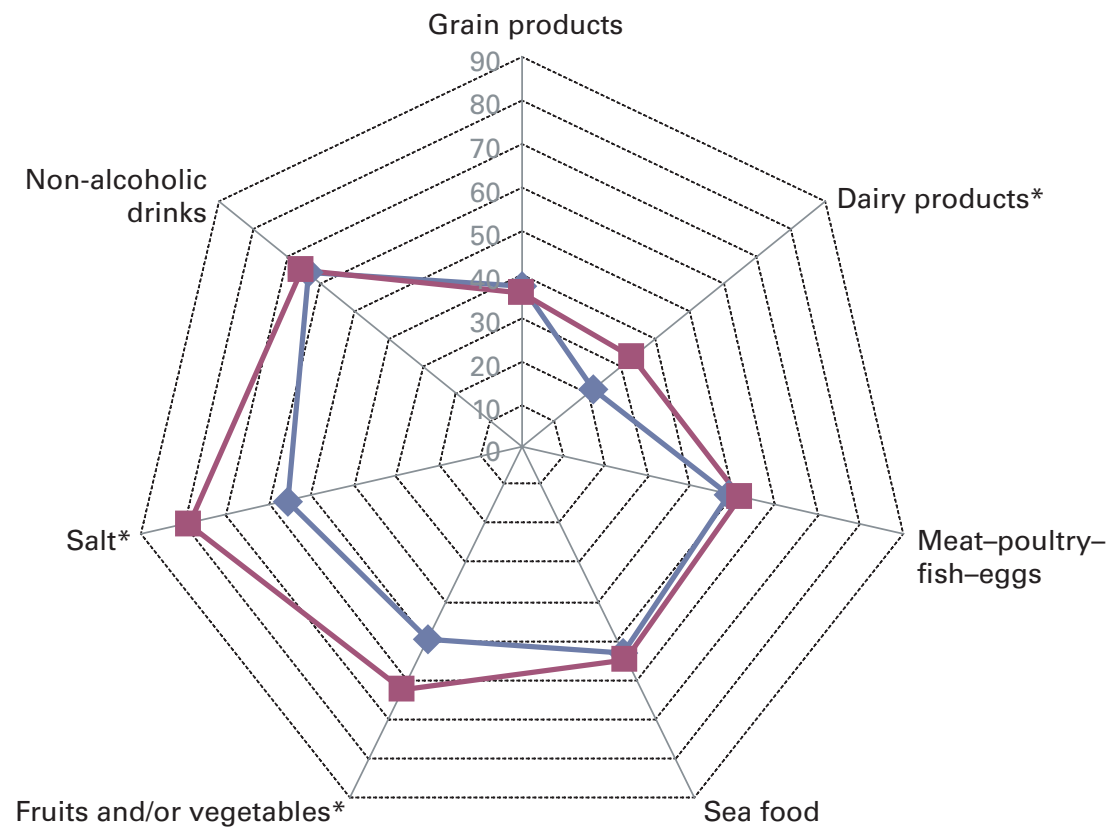

Fig. 1. Compliance with food-based guidelines according to sex: $(--)$, men; (-- ) , women. The radar chart plots the values of each dietary component along a separate axis that starts in the centre of the chart $(0 \%$ compliance) and ends at the outer ring $(100 \%$ compliance). The values are the percentage of the population adherent to each dietary recommendation. ${ }^{*} P<0.05$.

meals. Likewise, there was a significant relationship between adherence to dietary recommendations and BMI.

\section{Univariate analyses}

The univariate analyses revealed that getting older (OR 0.78 ; $95 \%$ CI $0.72,0.85$ ) and being of Portuguese origin (OR 0.57;
95\% CI $0.43,0.75)$ increased the likelihood of high scoring on the RCI. On the other hand, living alone $(P=0 \cdot 002)$, living below the poverty threshold $(P=0.032)$, being a smoker $(P<0.0001)$, and being not aware of the importance of a healthy diet $(P<0 \cdot 0001)$ were associated with lower RCI scores (poor compliance with national dietary recommendations) (Table 3).

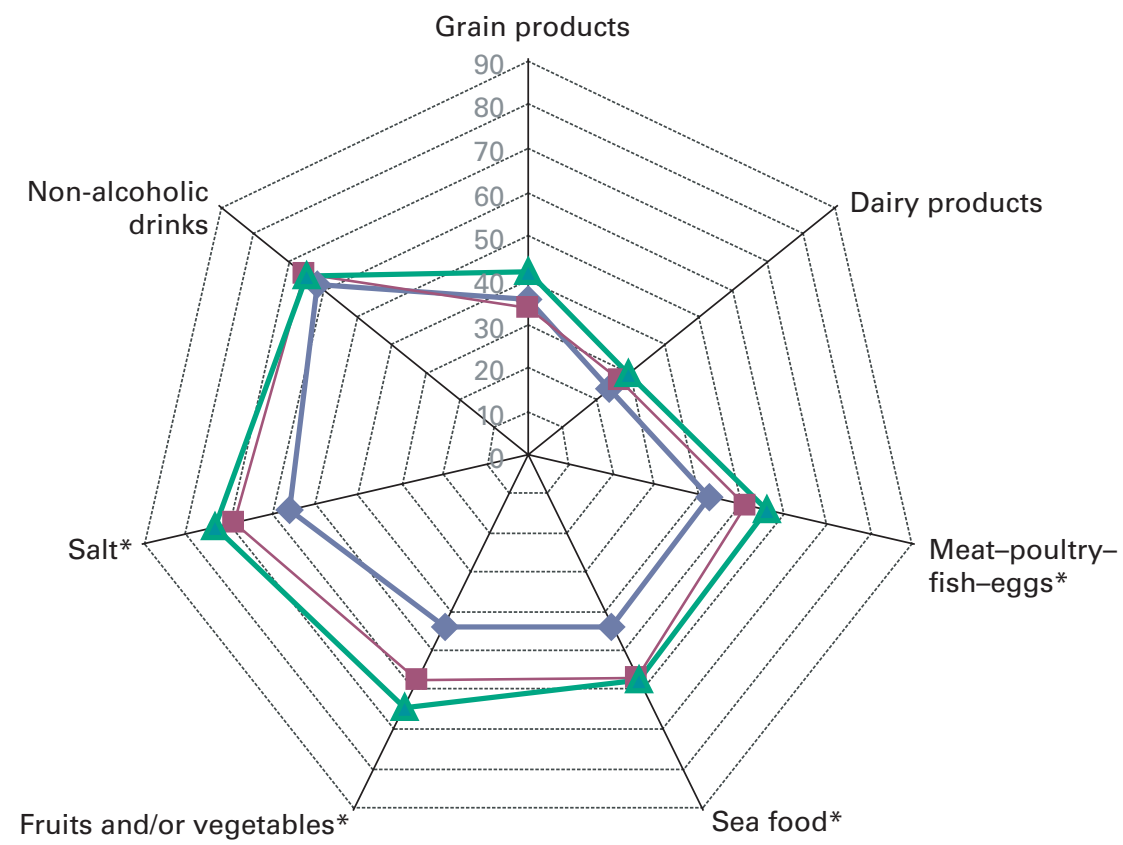

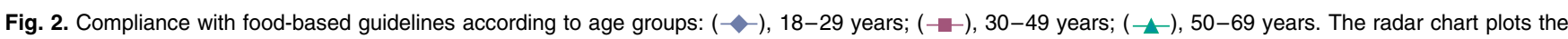
values of each dietary component along a separate axis that starts in the centre of the chart ( $0 \%$ compliance) and ends at the outer ring (100\% compliance). The values are the percentage of the population adherent to each dietary recommendation. ${ }^{*} P<0.05$. 


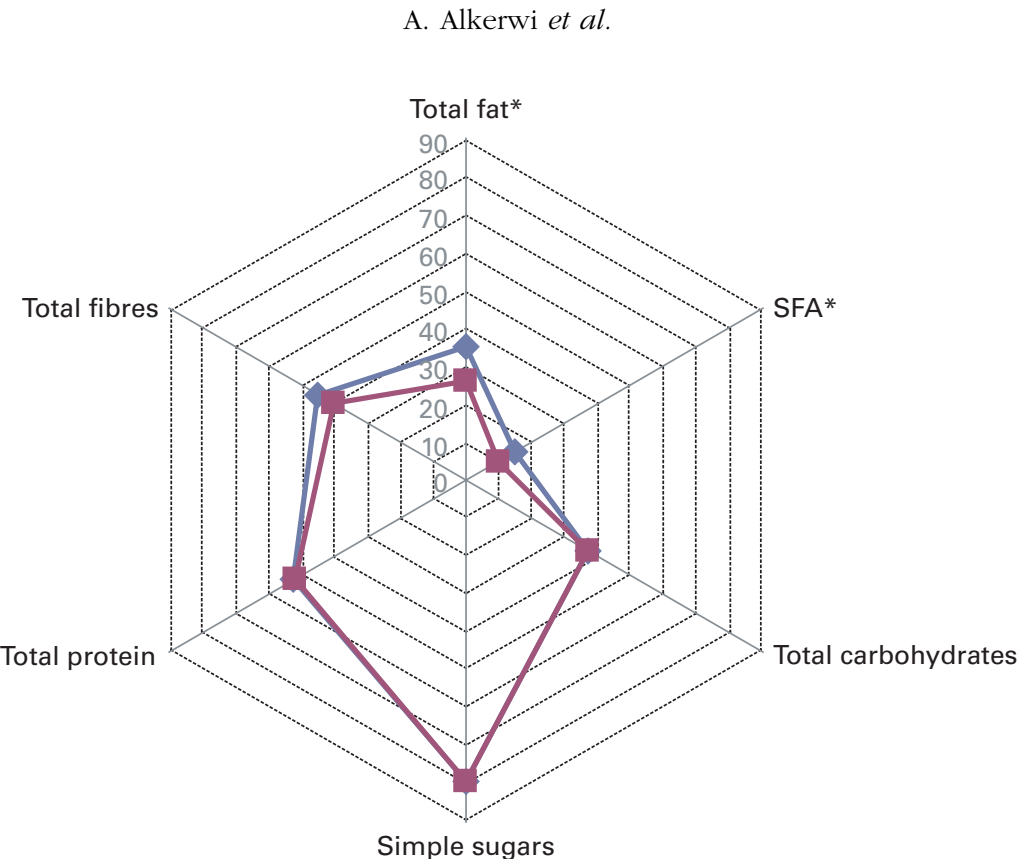

Fig. 3. Compliance with nutrient-based guidelines according to sex: $(--)$, men; (--), women. The radar chart plots the values of each dietary component along a separate axis that starts in the centre of the chart ( $0 \%$ compliance) and ends at the outer ring ( $100 \%$ compliance). The values are the percentage of the population adherent to each dietary recommendation. ${ }^{*} P<0.05$.

\section{Multivariate analyses}

In the final model, only the variables significantly associated with degree of compliance with dietary guidelines $(P<0.05)$ were included in the multivariate ordinal logistic regression analysis. After adjustment for potential confounding factors, six factors remained significantly and independently associated with dietary compliance, namely age, country of birth, economic status, smoking status, awareness of a healthy diet and BMI. Compliance increased with age (OR 0.81 for each 10-year addition; 95\% CI 0.74, 0.90), suggesting that individuals do respect the dietary guidelines better as they get older. Regarding the country of birth, the subjects born in Portugal showed better adherence to national dietary recommendations than natives of Luxembourg (OR 0.47;95\% CI $0.34,0.66)$. By contrast, smoking increased the risk of poor compliance as compared with non-smokers (OR 1.49; $95 \%$ CI $1 \cdot 14,1 \cdot 96$ ). Compared with those aware of the very high importance of balanced meals, subjects who attributed little importance or enough importance to balanced meals

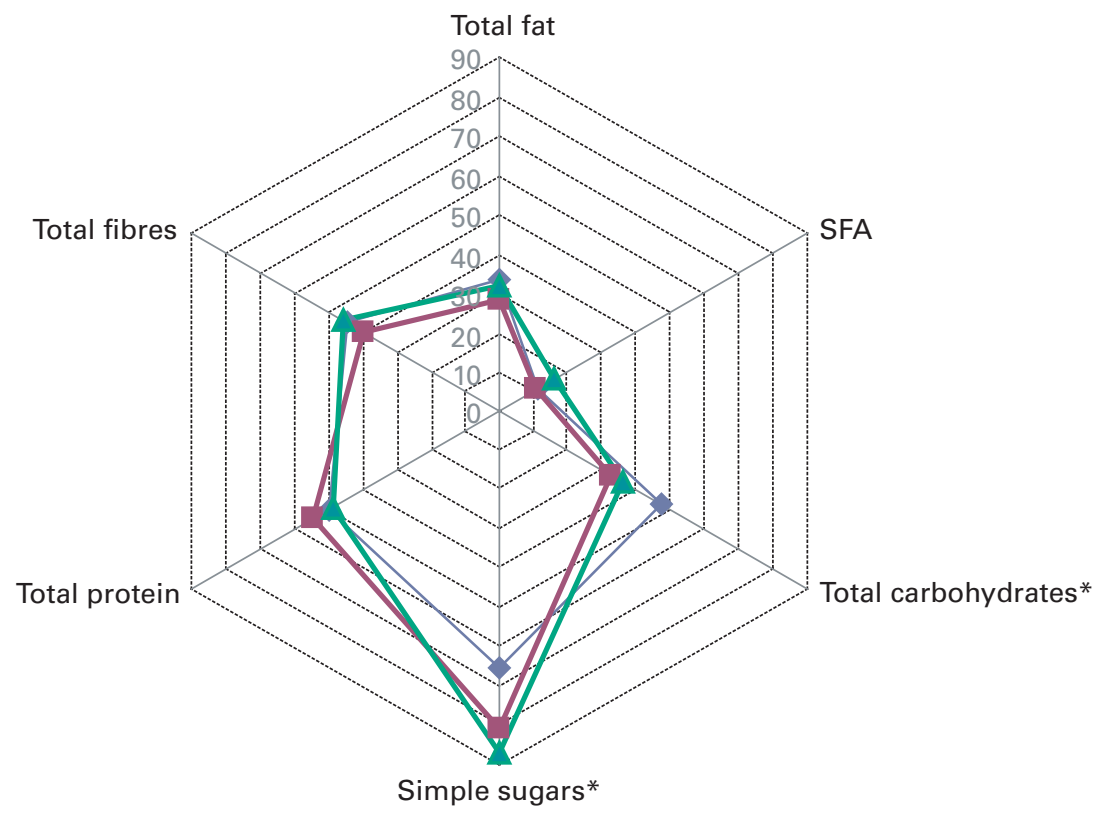

Fig. 4. Compliance with nutrient-based guidelines according to age groups: $(-\neg), 18-29$ years; $(--), 30-49$ years; $\left(-\uparrow_{-}\right)$, 50-69 years. The radar chart plots the values of each dietary component along a separate axis that starts in the centre of the chart ( $0 \%$ compliance) and ends at the outer ring (100\% compliance). The values are the percentage of the population adherent to each dietary recommendation. ${ }^{*} P<0.05$. 
Table 2. Distribution of recommendation compliance index-based compliance according to demographic, socio-economic, behavioural and health-related characteristics of participants in the Observation of Cardiovascular Risk Factors in Luxembourg (ORISCAV-LUX) study (Percentages and numbers of subjects by quartile (Q))

\begin{tabular}{|c|c|c|c|c|c|c|c|c|c|}
\hline \multirow[b]{2}{*}{ Characteristics } & \multicolumn{2}{|c|}{$\begin{array}{c}\text { Q1 (weak } \\
\text { compliance): }<5.50\end{array}$} & \multicolumn{2}{|c|}{ Q2: $5 \cdot 50-6.99$} & \multicolumn{2}{|c|}{ Q3: 6.99-8 } & \multicolumn{2}{|c|}{$\begin{array}{c}\text { Q4 (good } \\
\text { compliance): } \geq 8\end{array}$} & \multirow{2}{*}{$P$ for trend } \\
\hline & $\%$ & $n$ & $\%$ & $n$ & $\%$ & $n$ & $\%$ & $n$ & \\
\hline Subjects & 24.5 & 302 & $25 \cdot 5$ & 315 & $26 \cdot 7$ & 330 & $21 \cdot 2$ & 287 & \\
\hline \multicolumn{10}{|l|}{$\operatorname{Sex}(n 1234)$} \\
\hline Men & $26 \cdot 4$ & 148 & $26 \cdot 1$ & 156 & $26 \cdot 7$ & 167 & $20 \cdot 8$ & 129 & 0.42 \\
\hline Women & 24.7 & 154 & $25 \cdot 3$ & 159 & $26 \cdot 3$ & 163 & 23.6 & 158 & \\
\hline \multicolumn{10}{|l|}{ Age $(n 1234)$} \\
\hline $18-29$ years & 38.0 & 69 & $26 \cdot 5$ & 48 & $18 \cdot 1$ & 32 & 17.4 & 31 & $<0.0001$ \\
\hline $30-49$ years & 23.9 & 149 & $27 \cdot 3$ & 173 & 28.5 & 178 & $20 \cdot 3$ & 133 & \\
\hline $50-69$ years & $19 \cdot 4$ & 84 & $22 \cdot 5$ & 94 & $29 \cdot 3$ & 120 & $28 \cdot 8$ & 123 & \\
\hline \multicolumn{10}{|l|}{ Country of birth ( $n 1234)$} \\
\hline European & $25 \cdot 4$ & 68 & $22 \cdot 8$ & 62 & $25 \cdot 6$ & 69 & $26 \cdot 3$ & 76 & $<0.0001$ \\
\hline Non-European & 38.0 & 22 & 9.9 & 7 & 20.7 & 13 & $60.5(21$ & & \\
\hline Portugal & $12 \cdot 0$ & 19 & $25 \cdot 3$ & 35 & 36.9 & 53 & 24.9 & 38 & \\
\hline Luxembourg & $27 \cdot 0$ & 193 & 28.3 & 211 & $25 \cdot 3$ & 195 & 19.5 & 152 & \\
\hline \multicolumn{10}{|l|}{ Level of education ( $n$ 1225) } \\
\hline Primary & $26 \cdot 8$ & 83 & 24.7 & 79 & $27 \cdot 7$ & 85 & $20 \cdot 8$ & 71 & 0.14 \\
\hline Secondary & $27 \cdot 4$ & 145 & $25 \cdot 9$ & 145 & $25 \cdot 3$ & 149 & 21.4 & 127 & \\
\hline Tertiary & 21.5 & 72 & $26 \cdot 0$ & 88 & $27 \cdot 7$ & 94 & 24.9 & 87 & \\
\hline \multicolumn{10}{|l|}{ Conjugal status ( $n$ 1234) } \\
\hline Living with partner & $22 \cdot 4$ & 196 & $26 \cdot 0$ & 230 & 28.5 & 251 & $23 \cdot 1$ & 211 & 0.013 \\
\hline Living alone & $32 \cdot 6$ & 106 & $25 \cdot 0$ & 85 & $22 \cdot 2$ & 79 & $20 \cdot 2$ & 76 & \\
\hline \multicolumn{10}{|l|}{ Economic status ( $n$ 1082) } \\
\hline Living below the poverty threshold & $30 \cdot 1$ & 66 & $27 \cdot 3$ & 62 & 23.3 & 53 & $19 \cdot 3$ & 48 & 0.046 \\
\hline Living above the poverty threshold & 238 & 196 & $25 \cdot 6$ & 217 & $27 \cdot 7$ & 235 & $22 \cdot 9$ & 205 & \\
\hline \multicolumn{10}{|l|}{ Smoking status ( $n$ 1234) } \\
\hline Non-smokers & 23.1 & 218 & 24.7 & 240 & $27 \cdot 2$ & 266 & $25 \cdot 1$ & 257 & 0.004 \\
\hline Smokers & 34.6 & 84 & $29 \cdot 4$ & 75 & $24 \cdot 2$ & 64 & 11.8 & 30 & \\
\hline \multicolumn{10}{|l|}{ Importance of balanced meals ( $n$ 1233) } \\
\hline Very important & $19 \cdot 2$ & 118 & $24 \cdot 5$ & 156 & 28.5 & 181 & $27 \cdot 8$ & 183 & $<0.0001$ \\
\hline Enough importance & $30 \cdot 2$ & 154 & $25 \cdot 9$ & 135 & $25 \cdot 9$ & 138 & $17 \cdot 9$ & 100 & \\
\hline Little importance & $47 \cdot 7$ & 30 & 33.5 & 23 & $14 \cdot 0$ & 11 & 4.8 & 4 & \\
\hline \multicolumn{10}{|l|}{$\mathrm{BMI}(n$ 1234) } \\
\hline Underweight & $54 \cdot 7$ & 11 & $26 \cdot 5$ & 5 & $14 \cdot 7$ & 3 & 4.0 & 1 & $<0.0001$ \\
\hline Normal weight & $29 \cdot 3$ & 147 & $26 \cdot 0$ & 137 & 24.5 & 129 & $20 \cdot 2$ & 115 & \\
\hline Overweight & 23.9 & 97 & $25 \cdot 6$ & 103 & $27 \cdot 2$ & 114 & $23 \cdot 3$ & 100 & \\
\hline Obese & $17 \cdot 0$ & 47 & $25 \cdot 1$ & 70 & 31.1 & 84 & $26 \cdot 8$ & 71 & \\
\hline
\end{tabular}

had about, respectively, 3-fold and 2-fold increased chances of being less compliant. Obese subjects exhibited higher RCI scores (good compliance) than subjects with normal weight (OR 0.68; $95 \%$ CI 0.50, 0.92) (Table 3).

\section{Discussion and applications}

The present study provides novel data on the population adherence to national dietary guidelines in a representative sample of the adult population in Luxembourg. It measured for the first time the current gap in compliance with key national dietary guidelines among adults, and examined the demographic, socio-economic, behavioural and health-related factors that might explain poor compliance.

Compared with American and other European nutrition programmes, our national plan for healthy nutrition focused principally on the essential food- and nutrient-related guidelines to ensure a global adequate health status. The present findings provide evidence that several national dietary guidelines are not sufficiently respected compared with others. The greatest gaps occur in the adherence to grain and dairy product consumption guidelines, as well as to total fat and notably to the SFA recommendations. Globally, subjects should increase their intake of grains and dairy products and reduce their consumption of total fat and of SFA in particular.

Although no significant sex-specific difference was observed, compliance markedly increased with age; older individuals were more inclined to comply well. In line with this finding, several studies suggested that increasing age was associated with an increase intake of fruits and vegetables ${ }^{(23,24)}$ and with reporting a healthier $\operatorname{diet}^{(25)}$.

Adequate dietary intake is essential to health promotion. Low mortality in different populations ${ }^{(26)}$, notably the Mediterranean $^{(27)}$, has been associated with greater adherence to healthy dietary patterns. Although extensive worldwide research studies have been conducted on the links between nutrients, food patterns and chronic diseases ${ }^{(28-32)}$, the best way to assess population adherence to dietary recommendations and adequate dietary intake is still unknown. Several investigators used dietary scores to characterise the diet that 
Table 3. Demographic, socio-economic, behavioural and health-related determinants of weak dietary compliance of participants in the Observation of Cardiovascular Risk Factors in Luxembourg (ORISCAV-LUX) study*

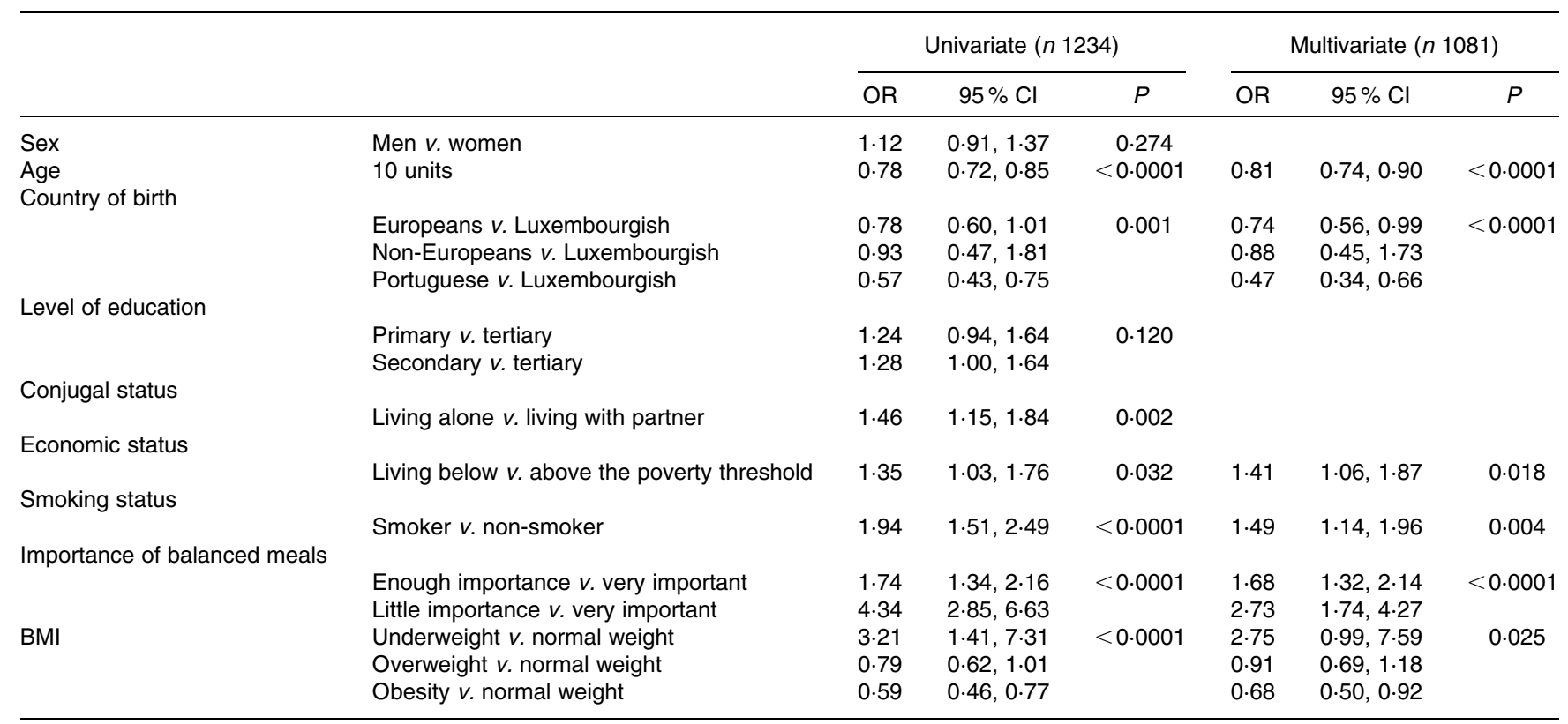

* Non-significant variables were omitted from the multivariate analyses.

reflects healthy behaviours. Most of these tools were developed in terms of adherence to the American dietary guidelines ${ }^{(33-36)}$ and recently to the French Nutrition and Health Programme Recommendations ${ }^{(20)}$. The purpose of the present study was to describe how closely the adult population adhered to national food- and nutrient-based recommendations. The national dietary guidelines considered specific food groups and macronutrients as the best indicators of a healthy diet; therefore, a weak compliance can inform on an inadequate dietary intake. In some ways, the RCI indicates how healthily individuals eat, since dietary compliance and healthy eating are obviously connected. In opposition to other previous studies, our findings voluntarily did not focus on the gap between estimated average intake of individual food or nutrients compared with the dietary guidelines. This approach may generate a bias due to the asymmetric nature of food and nutrient intake variables. The percentage of individuals conforming to each national dietary recommendation is more relevant to assess the overall picture of dietary consumption and to track the population adherence to dietary guidelines.

In line with scores developed by other researchers, the RCI attributes added points for higher fruit and vegetable intake, and negative points for higher salt intake than the currently provided recommendations, to take into account healthy behaviours $^{(20,36,37)}$. Moreover, the RCI takes into account energy intake and the problem of overestimated self-reported consumption. Points were deducted for individuals with energy intakes greater than their estimated needs. Schofield's equation based on age, body weight and height was used to estimate each individual's BMR. Individual energy expenditures $($ BMR $\times$ physical activity level) were then compared with energy intakes. If reported energy intake was $>5 \%$ of the calculated energy need, the total score was reduced by the same proportion ${ }^{(20)}$.

Significant socio-economic differentials in dietary patterns have been shown in New Zealand ${ }^{(38)}$, the Republic of Ireland ${ }^{(39)}$ and Denmark ${ }^{(40)}$. Level of education was the most important variable explaining social differences in dietary habits among the Danish adults ${ }^{(40)}$. In an American study, sex, age, race/ethnicity, education and income were factors that influenced diet quality ${ }^{(41)}$, whereas lower occupational categories were associated with poorer dietary quality in a French study $^{(14)}$. In our studied population, after adjusting for all potential confounders, individuals living below the poverty threshold were significantly less compliant with the national dietary guidelines, hence emphasising the importance of socio-economic status in determining the degree of adherence to national recommendations.

The crude analyses of the RCI revealed that the degree of compliance differed according to demographic and behavioural characteristics; subjects with the lowest scores were generally young, living alone, had a lower economic and educational level, were smokers, and attributed little importance to a balanced diet. However, the significant effects of marital status and educational level disappeared when adjusting for other variables. Consequently, only age, country of birth, economic status, smoking status, BMI, and subject's awareness of the importance of balanced meals emerged as independent factors associated with poor dietary compliance, after full adjustment for other potential confounding factors. We found that smokers had a general tendency to be reluctant to health-promoting behaviours as compared with others. Thus, national public health policies need to target those most at risk: the young, smokers and particularly less healthconscious individuals, as they have the least will to change 
their habits. Similar to French study findings, obese subjects were more likely to be better compliers with national dietary guidelines than subjects with a normal weight. This is probably due to their early awareness of body fatness which led them to change their eating habits accordingly. The cross-sectional nature of the present study hinders confirmation of the cause-effect relationship.

Although results obtained here were globally consistent with those of other studies, the diversity of approaches to designing dietary scores makes direct comparison with other studies difficult. Mostly, all scores were developed based on each country's national recommendations, which differ between countries; some dietary guidelines are based on only food groups, others on food and nutrient intakes. The absence of a reliable tool for dietary assessment in epidemiological studies constitutes a major obstacle hampering international comparisons.

The ORISCAV-LUX study is characterised by several strong points ${ }^{(6,7,10)}$; however, certain shortcomings should be recognised, as with other nutrition-related studies. Although the FFQ has been largely used in cross-sectional studies, the data on dietary intake are still based on self-report with the possibility of under- or over-reporting. Additionally, we are aware of the potential limits of the RCI, which may provide a partial image of overall diet quality. However, it helped to distinguish the population's degree of adherence to the current national guidelines and identify the associated socioeconomic and behavioural characteristics, corresponding to our research objectives. From a public health standpoint, the RCI was designed to provide an overall easy but coherent picture of the people's compliance with the key national food- and nutrient-related recommendations, rather than to measure diet quality, which requires more sophisticated tools. Despite these limitations, the present findings are useful and represent a valid source of information for health professional and public health decision-makers.

The present study identified, for the first time in Luxembourg, current population compliance gaps by using radar charts. These illustrations, barely used in the literature, helped to display, at a glance, a comprehensive assessment of the current situation regarding the population compliance with individual dietary recommendations. In consistent with our public health perspectives, presenting data in the form of radar charts serves as a tool of communication to support decision-makers engaged in strategic planning, and health professionals to understand where input should be improved, and efforts should be focused.

In addition, the study was based on a global approach emphasising both the adherence to food recommendations that reflect appropriate food selection, and the adherence to nutrient recommendations that reflect good-quality dietary intake. The multidimensional nature of dietary compliance analysis allowed evaluation of the total population diet adequacy rather than the examination of single food groups in isolation.

In conclusion, the present study showed that a substantial proportion of the population of adult residents of Luxembourg exhibits a poor to moderate compliance with the current national dietary guidelines. This implies that dietary habits of adults ought to be improved. In addition, the segment of the population with poor compliance is represented by young adults, the deprived, smokers and those unaware of the importance of a balanced diet to maintain good health. This underscores the need for targeted nutrition interventions to tackle those at particularly high risk. Therefore, these findings should be of high interest not only to decision-makers but also to several public health actors and stakeholders, such as health educators, dietitians and teachers. The magnitude of the gap between current dietary intakes and the national recommendations calls for a continued effort to increase the population awareness of the importance of a healthy and balanced diet.

\section{Acknowledgements}

The present study was supported by a research grant from the National Fund of Research (Fond National de Recherche; project MSF, 784844, BM). A. Alkerwi was involved in the conception and design of the ORISCAV-LUX survey, coordinated the field data collection, conceived the present research, contributed to data analyses and drafted the manuscript. N. S. and A. N. performed the statistical analyses and critical discussion of the results. M.-L. L. was involved in the instigation of the ORISCAV-LUX study. A. Albert contributed to the critical revision of the manuscript. M. G. provided expertise and oversight on the intellectual content. All of the authors reviewed drafts and approved the final version of the manuscript. There are no conflicts of interest.

\section{References}

1. Yarnell J, Yu S, McCrum E, et al. (2005) Education, socioeconomic and lifestyle factors, and risk of coronary heart disease: the PRIME Study. Int J Epidemiol 34, 268-275.

2. World Health Organization (2003) Diet, Nutrition and the Prevention of Chronic Diseases. Joint WHO/FAO Expert Consultation. WHO Technical Report Series no. 916. Geneva: WHO.

3. Brundtland GH (2002) From the World Health Organization. Reducing risks to health, promoting healthy life. JAMA $\mathbf{2 8 8}$, 1974.

4. National Statistical Institute STATEC (2011) Luxembowg in Figures. http://www.statec.public.lu/en/publications/index.html

5. Anonymous (2006) Statistiques des causes de décès (National Statistics of all Causes of Death). Luxembourg: Directorate of Health, Ministry of Health.

6. Alkerwi A, Sauvageot N, Donneau AF, et al. (2010) First nationwide survey on cardiovascular risk factors in GrandDuchy of Luxembourg (ORISCAV-LUX). BMC Public Health 10, 468.

7. Alkerwi A, Donneau AF, Sauvageot N, et al. (2011) Prevalence of the metabolic syndrome in Luxembourg according to the Joint Interim Statement definition estimated from the ORISCAV-LUX study. BMC Public Health 11, 4.

8. Sharkey JR, Branch LG, Zohoori N, et al. (2002) Inadequate nutrient intakes among homebound elderly and their correlation with individual characteristics and health-related factors. Am J Clin Nutr 76, 1435-1445. 
9. Sharma S, De Roose E, Cao X, et al. (2009) Dietary intake in a population undergoing a rapid transition in diet and lifestyle: the Inuvialuit in the Northwest Territories of Arctic Canada. Can J Public Health 100, 442-448.

10. Alkerwi A, Sauvageot N, Couffignal S, et al. (2010) Comparison of participants and non-participants to the ORISCAV-LUX population-based study on cardiovascular risk factors in Luxembourg. BMC Med Res Methodol 10, 80.

11. Alkerwi A, Donneau AF, Sauvageot N, et al. (2011) Dietary, behavioural and socio-economic determinants of the metabolic syndrome among adults in Luxembourg: findings from the ORISCAV-LUX study. Public Health Nutr (epublication ahead of print version 14 September 2011)

12. World Health Organization (2000) Obesity: Preventing and Managing the Global Epidemic. Report of a WHO Consultation. WHO Technical Report Series no. 894. Geneva: WHO

13. Shatenstein B, Nadon S, Godin C, et al. (2005) Development and validation of a food frequency questionnaire. Can J Diet Pract Res 66, 67-75.

14. Malon A, Deschamps V, Salanave B, et al. (2010) Compliance with French nutrition and health program recommendations is strongly associated with socioeconomic characteristics in the general adult population. J Am Diet Assoc 110, 848-856.

15. Hercberg S, Deheeger M \& Preziosi P (2002) SU.VI.MAX. Portions alimentaire. Manual photos pour l'estimation des quantités (SU.VI.MAX. Food Portions. Photo Manual for the Estimation of Quantities). Paris: Poly Technica.

16. Hercberg S (2006) SU.VI.MAX. Tables de composition des aliments (SU.VI.MAX. Food Composition Tables). Paris: Inserm.

17. Luxembourg Ministry of Health (2006) Vers un plan national alimentation saine et activité physique (PNS 2006-2012) (Towards a National Healthy Food and Physical Activity Plan (PNS 2006-2012)). Luxembourg: Ministry of Health. http://www.sante.public.lu

18. Rumawas ME, Dwyer JT, McKeown NM, et al. (2009) The development of the Mediterranean-style dietary pattern score and its application to the American diet in the Framingham Offspring Cohort. J Nutr 139, 1150-1156.

19. Guenther PM, Reedy J \& Krebs-Smith SM (2008) Development of the Healthy Eating Index-2005. J Am Diet Assoc 108, 1896-1901.

20. Estaquio C, Kesse-Guyot E, Deschamps V, et al. (2009) Adherence to the French Programme National Nutrition Santé Guideline Score is associated with better nutrient intake and nutritional status. J Am Diet Assoc 109, 1031-1041.

21. Hagstromer M, Oja P \& Sjostrom M (2006) The International Physical Activity Questionnaire (IPAQ): a study of concurrent and construct validity. Public Health Nutr 9, 755-762.

22. IPAQ Research Committee (2005) Guidelines for data processing and analysis of the International Physical Activity Questionnaire (IPAQ) - short and long forms. http://www.ipaq. ki.se/scoring.pdf (accessed January 2012).

23. Dynesen AW, Haraldsdottir J, Holm L, et al. (2003) Sociodemographic differences in dietary habits described by food frequency questions - results from Denmark. Eur J Clin Nutr 57, 1586-1597.
24. Wandel M (1995) Dietary intake of fruits and vegetables in Norway: influence of life phase and socio-economic factors. Int J Food Sci Nutr 46, 291-301.

25. Hjartaker A \& Lund E (1998) Relationship between dietary habits, age, lifestyle, and socio-economic status among adult Norwegian women. The Norwegian Women and Cancer Study. Eur J Clin Nutr 52, 565-572.

26. Huijbregts P, Feskens E, Rasanen L, et al. (1997) Dietary pattern and 20 year mortality in elderly men in Finland, Italy, and The Netherlands: longitudinal cohort study. BMJ 315, 13-17.

27. Trichopoulou A, Costacou T, Bamia C, et al. (2003) Adherence to a Mediterranean diet and survival in a Greek population. N Engl J Med 348, 2599-2608.

28. Wirfalt E, Hedblad B, Gullberg B, et al. (2001) Food patterns and components of the metabolic syndrome in men and women: a cross-sectional study within the Malmo Diet and Cancer cohort. Am J Epidemiol 154, 1150-1159.

29. Esposito K, Marfella R, Ciotola M, et al. (2004) Effect of a Mediterranean-style diet on endothelial dysfunction and markers of vascular inflammation in the metabolic syndrome: a randomized trial. JAMA 292, 1440-1446.

30. Azadbakht L, Mirmiran P, Esmaillzadeh A, et al. (2005) Dairy consumption is inversely associated with the prevalence of the metabolic syndrome in Tehranian adults. Am J Clin Nutr 82, 523-530.

31. Hu FB (2002) Dietary pattern analysis: a new direction in nutritional epidemiology. Curr Opin Lipidol 13, 3-9.

32. Lutsey PL, Steffen LM \& Stevens J (2008) Dietary intake and the development of the metabolic syndrome: the Atherosclerosis Risk in Communities Study. Circulation 117, 754-761.

33. Patterson RE, Haines PS \& Popkin BM (1994) Diet quality index: capturing a multidimensional behavior. $J$ Am Diet Assoc 94, 57-64.

34. Haines PS, Siega-Riz AM \& Popkin BM (1999) The Diet Quality Index revised: a measurement instrument for populations. J Am Diet Assoc 99, 697-704.

35. Kennedy ET, Ohls J, Carlson S, et al. (1995) The Healthy Eating Index: design and applications. J Am Diet Assoc 95, 1103-1108.

36. Fogli-Cawley JJ, Dwyer JT, Saltzman E, et al. (2006) The 2005 Dietary Guidelines for Americans Adherence Index: development and application. J Nutr 136, 2908-2915.

37. Moeller SM, Reedy J, Millen AE, et al. (2007) Dietary patterns: challenges and opportunities in dietary patterns research an Experimental Biology workshop, April 1, 2006. J Am Diet Assoc 107, 1233-1239.

38. Metcalf P, Scragg R \& Davis P (2006) Dietary intakes by different markers of socioeconomic status: results of a New Zealand workforce survey. N Z Med J 119, U2127.

39. Friel S, Kelleher CC, Nolan G, et al. (2003) Social diversity of Irish adults nutritional intake. Eur J Clin Nutr 57, 865-875.

40. Groth MV, Fagt S \& Brondsted L (2001) Social determinants of dietary habits in Denmark. Eur J Clin Nutr 55, 959-966.

41. Popkin BM, Siega-Riz AM \& Haines PS (1996) A comparison of dietary trends among racial and socioeconomic groups in the United States. N Engl J Med 335, 716-720. 